\title{
Assessing the Battery Cost at Which Plug-in Hybrid Medium-Duty Parcel Delivery Vehicles Become Cost-Effective
}

\author{
Laurie A. Ramroth, Jeffrey D. Gonder, Aaron D. Brooker \\ National Renewable Energy Laboratory
}

Copyright $(\odot) 2013$ SAE International

\section{$\underline{\text { ABSTRACT }}$}

The National Renewable Energy Laboratory (NREL) validated conventional diesel and diesel-hybrid, medium-duty parcel delivery vehicle models to evaluate petroleum reductions and cost implications of hybrid and plug-in hybrid diesel variants. The hybrid and plug-in hybrid variants are run on a field dataderived design matrix to analyze the effect of drive cycle, distance, engine downsizing, battery replacements, and battery energy on fuel consumption and lifetime cost. For an array of diesel fuel costs, the battery cost per kilowatt-hour at which the hybridized configuration becomes cost-effective is calculated. The results build on a previous analysis that found the fuel savings from medium-duty, plug-in hybrids more than offset vehicle incremental price for future battery and fuel cost projections; however, they seldom did so under present day cost assumptions in the absence of purchase incentives. The results also highlight the importance of understanding the application's drive-cycle-specific daily distance and kinetic intensity.

\section{INTRODUCTION}

Commercial vehicles consume a significant amount of petroleum and emit a large amount of greenhouse gas emissions. Fortunately, medium-duty vehicles in the parcel delivery vocation are good candidates for electric drivetrains because they often share the following characteristics:

- Daily driving routes that return to a central depot, facilitating overnight charging
- Stop-and-go drive cycles that allow for energy capture from regenerative braking

- A buyer that more heavily values the bottom line over other factors

- Fuel savings that can multiply across an entire for-hire/ private fleet.

This investigation identifies the break-even point for the cost of the battery per kilowatt-hour $(\mathrm{kWh})$ for achieving payback relative to the baseline conventional vehicle.

\section{APPROACH}

Completing this study involved collaboration between multiple focus areas supported by the Vehicle Systems Simulation and Testing (VSST) activity within the U.S. Department of Energy (DOE) Vehicle Technologies Program. As described below, these included modeling, simulation and system optimization conducted by NREL's Vehicle Systems Analysis team, in-field vehicle evaluations by NREL's Fleet Test and Evaluation Team, and chassis dynamometer vehicle testing by NREL's Renewable Fuels and Lubricants (ReFUEL) Laboratory $[1,2, \underline{3}]$. In this analysis, battery life, cost, and fuel consumption tradeoffs are compared for various hybrid electric vehicle (HEV) and plug-in hybrid electric vehicle (PHEV) scenarios (referred to collectively as $\mathrm{P} / \mathrm{HEV}$ ) relative to a conventional diesel vehicle.

This section describes the approaches to conventional and hybrid vehicle model development and validation, development of the PHEV model, field data framing the analysis, and the development of the design and cost matrix. 


\section{Conventional and Hybrid Model Development and Validation}

The models for this analysis were developed in the Future Automotive Systems Technology Simulator (FASTSim) [4] using basic component specifications, engine-specific efficiency data when available, drive-train-specific accessory loads, and comparison to the second-by-second data from the ReFUEL Laboratory testing.

The ReFUEL Laboratory collected data from two parcel delivery vehicles owned and operated by United Parcel Service (UPS), which were transported to the ReFUEL Laboratory for fuel economy and emissions testing on the chassis dynamometer. Both the conventional and hybrid diesel vehicles used the same 149-kW engine. The hybrid electric van was equipped with a parallel hybrid system from Eaton. The ReFUEL Laboratory tested the vehicles on three cyclesthe New York Composite Cycle (NYComp), the Heavy HeavyDuty Diesel Truck (HHDDT), and the HTUF 4 (developed by the Hybrid Truck Users Forum) [5] .

$\underline{\text { Table } 1}$ and Figure 1, Figure 2, and Figure 3 detail the cycles used in the dynamometer testing. Table 2 provides details about specific vehicle and component specifications for each of the drivetrains, including the gross vehicle weight rating (GVWR). Accessory loads were adjusted based on ReFUEL vehicle fuel consumption test data at idle.

Figure 4 shows good agreement between the fuel consumption predicted by the models and the measurements that were recorded at the ReFUEL Laboratory. The discrepancies between the modeled and the experimentally measured values are slightly higher for the hybrid than for the conventional vehicle, but in all cases, the disagreement is less than $10 \%$.

Table 1. Cycles Used for ReFUEL Testing

\begin{tabular}{|l|l|l|c|}
\hline Cycle & $\begin{array}{l}\text { Average } \\
\text { Driving Speed } \\
\text { (when speed }> \\
\text { zero) }[\mathbf{m p h}]\end{array}$ & $\begin{array}{l}\text { Average } \\
\text { Speed } \\
\text { (includes } \\
\text { idle time) } \\
\text { [mph] }\end{array}$ & $\begin{array}{l}\text { Distance } \\
\text { [miles] }\end{array}$ \\
\hline NYComp & 13.11 & 8.75 & 2.50 \\
\hline HHDDT & 35.59 & 26.01 & 26.05 \\
\hline HTUF 4 & 22.49 & 12.05 & 11.17 \\
\hline
\end{tabular}

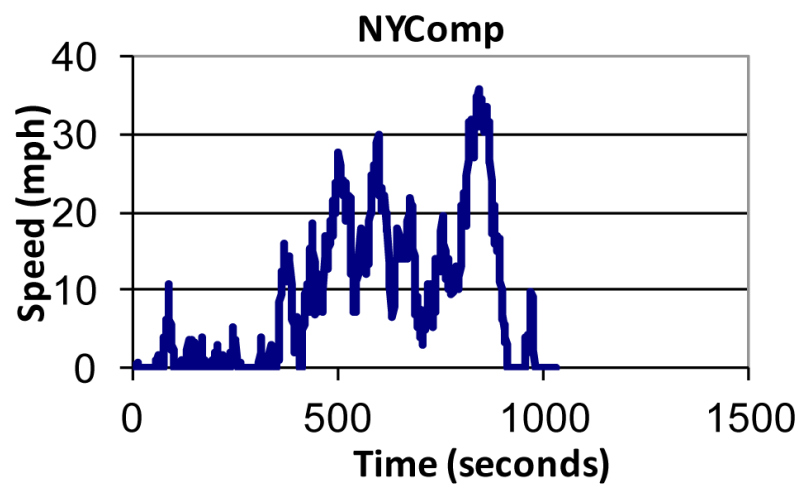

Figure 1. NYComp profile

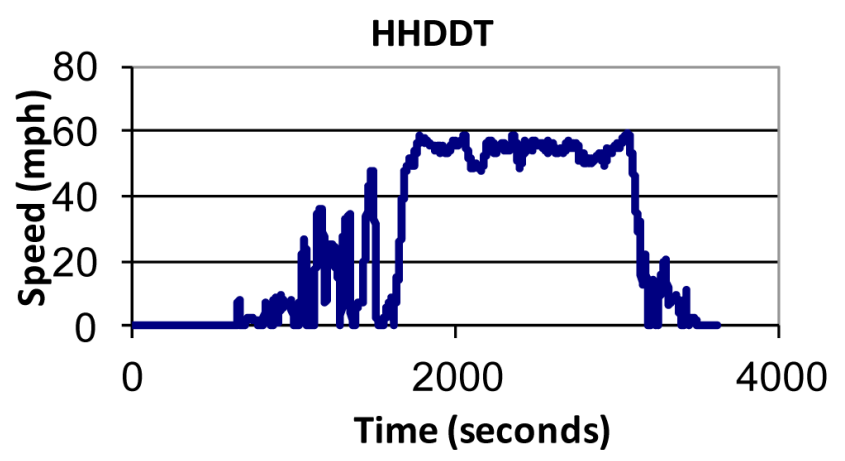

Figure 2. HHDDT profile

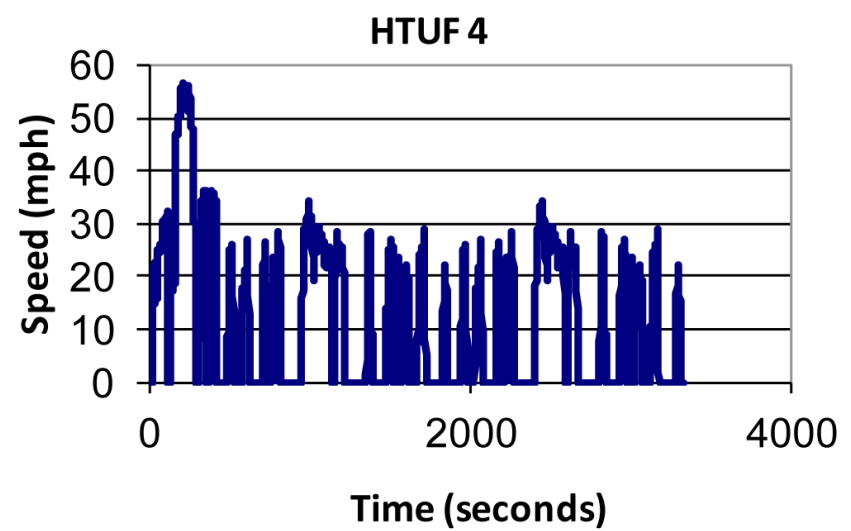

Figure 3. HTUF 4 profile

Table 2. General Vehicle/Component-Level Specifications

\begin{tabular}{lcc}
\hline & $\begin{array}{c}\text { Diesel } \\
\text { Conventional }\end{array}$ & $\begin{array}{c}\text { Diesel } \\
\text { Hybrid }\end{array}$ \\
\hline $\begin{array}{l}\text { Test weight } \\
\text { GVWR }\end{array}$ & $6,813 \mathrm{~kg}$ & $7,303 \mathrm{~kg}$ \\
Coefficient of drag & $10,433 \mathrm{~kg}$ & $10,433 \mathrm{~kg}$ \\
frontal area & 0.5 & 0.5 \\
Wheel rolling & $7.80 \mathrm{~m}^{2}$ & $7.80 \mathrm{~m}^{2}$ \\
resistance & 0.01 & 0.01 \\
Battery energy & & $1.8 \mathrm{kWh}$ \\
Engine power & $149 \mathrm{~kW}$ & $149 \mathrm{~kW}$ \\
Motor power & & $26 \mathrm{~kW}$ \\
Accessory load & $10 \mathrm{~kW}$ & $4 \mathrm{~kW}$ \\
\hline
\end{tabular}




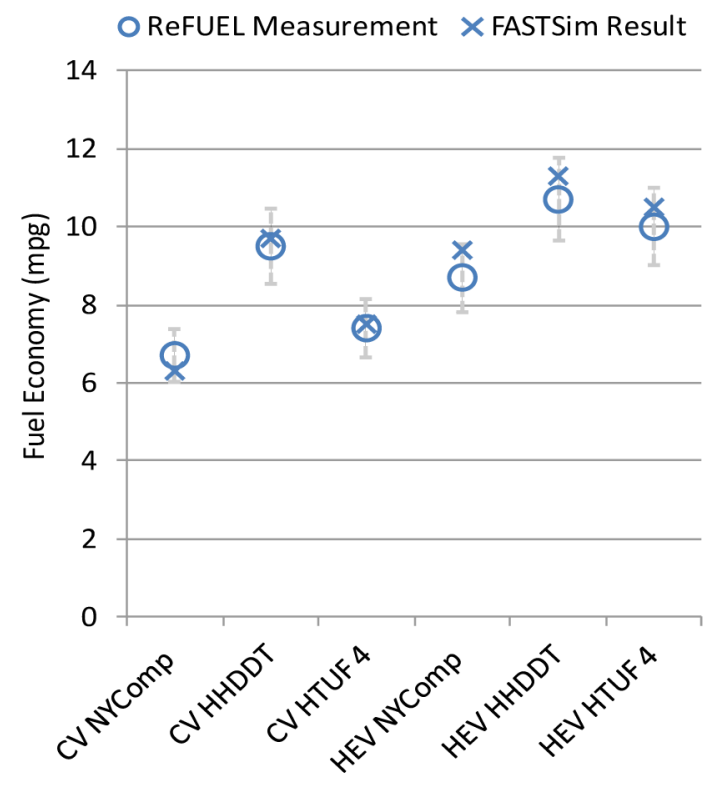

Figure 4. Validation of conventional and hybrid vehicle models

\section{Development of the Plug-In Hybrid Model}

A PHEV version of the model was developed based on the diesel-hybrid template. All PHEV scenarios included in the analysis were assumed to recharge once per day (overnight).

To make the PHEVs comparable, the Vehicle Systems Analysis team applied similar vehicle-specific parameters, and matched the engine power to that of the diesel hybrid and conventional vehicles $(149 \mathrm{~kW})$ for one set of simulations. In order to evaluate the additional fuel savings potential from engine downsizing, a second set of simulations was run with the engine power decreased by $20 \%$ to $120 \mathrm{~kW}$. It should be noted, however, that fleet managers interviewed as part of this study articulated minimum vehicle performance criteria that suggest any appreciable engine downsizing may result in unacceptable vehicle performance (particularly with respect to the continuous power requirement to maintain speed up a long grade). For this reason, the presented results focus primarily on the nondownsized (149-kW engine) simulation results.

The mass of the PHEVs is based on the mass of the diesel hybrid with an appropriate adjustment for the additional battery energy. Battery power was matched to motor power through motor efficiency. In a previous PHEV parcel delivery study, the Vehicle Systems Analysis team used $2.5 \mathrm{kWh}$ for the battery energy. This is the starting point for the additional battery energy used in this analysis.

\section{Field Data Framing the Analysis}

The NREL Fleet Test and Evaluation team maintains a data center of field drive-cycle and performance data collected from vehicles operated by partnering companies such as UPS and Federal Express, the top two for-hire carriers. This project leveraged a subset of the archived delivery fleet data, which was recorded using data loggers from ISAAC Instruments and appeared to have the best data quality. For this subset, over a month of drive-cycle data was collected for 11 vehicles instrumented with Global-Positioning System (GPS)-enabled data loggers. The data were the basis of a previous investigation, in which NREL used a frequency distribution of kinetic intensity and daily distance traveled to guide the selection of stock cycles and driving distances used in the analysis $[\underline{6}, \underline{7}]$. Kinetic intensity is a metric derived from the road load equation that represents the relative dominance of acceleration versus aerodynamic drag on vehicle power demand; it has been shown to positively correlate with hybridization benefit.

For this updated investigation, NREL also considered the range of field-cycle fuel consumption to guide selection of stock cycles for use in the broader design analysis. Figure 5 shows the range fuel consumption from the field cycles (directly measured with the ISAAC loggers) compared to the fuel consumption of the conventional vehicle model simulated in a batch mode over the same on-road speed profiles. Note that the actual payload mass of the vehicles in the field is unknown, so the simulations were performed using a typical average payload of 2,000 lbs. In spite of this uncertainty, the measured and simulated fuel consumption results show good agreement.

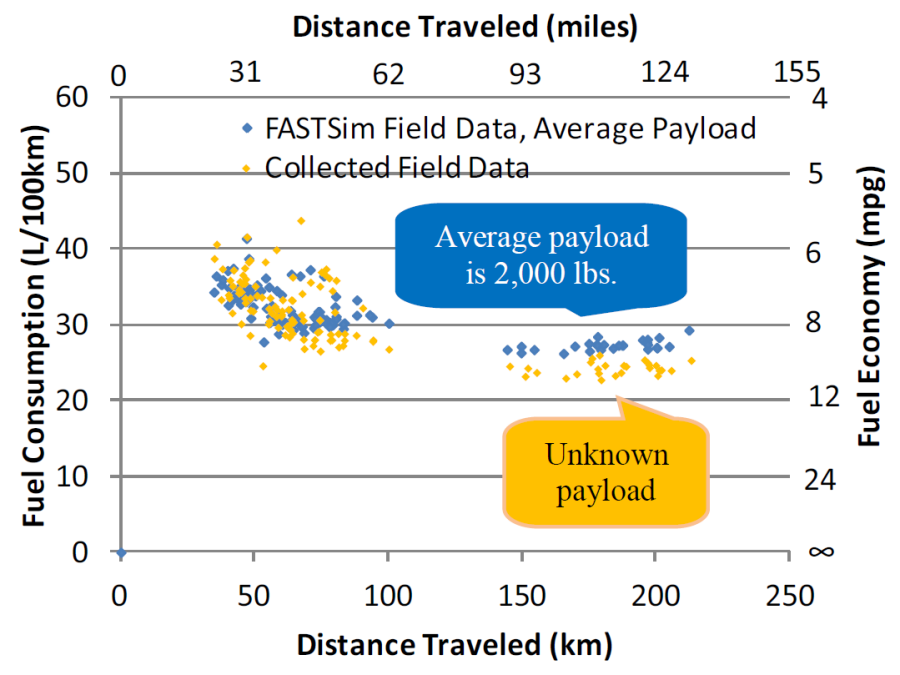

Figure 5. FASTSim batch mode simulation comparison to real-world field data for the conventional diesel vehicle 
Figure 6 overlays on the field results the modeled vehicle's fuel consumption over the three stock cycles used in the previous analysis-the HTUF 4, the heavy-duty Urban Dynamometer Driving Schedule (UDDS HD), and the Orange County Bus (OC Bus). Note from Figure 6 and Figure 7 that the addition of the NYComp cycle covers those field cycles that travel shorter distances and experience a large number of stops per mile (resulting in high fuel consumption for the baseline conventional vehicle).

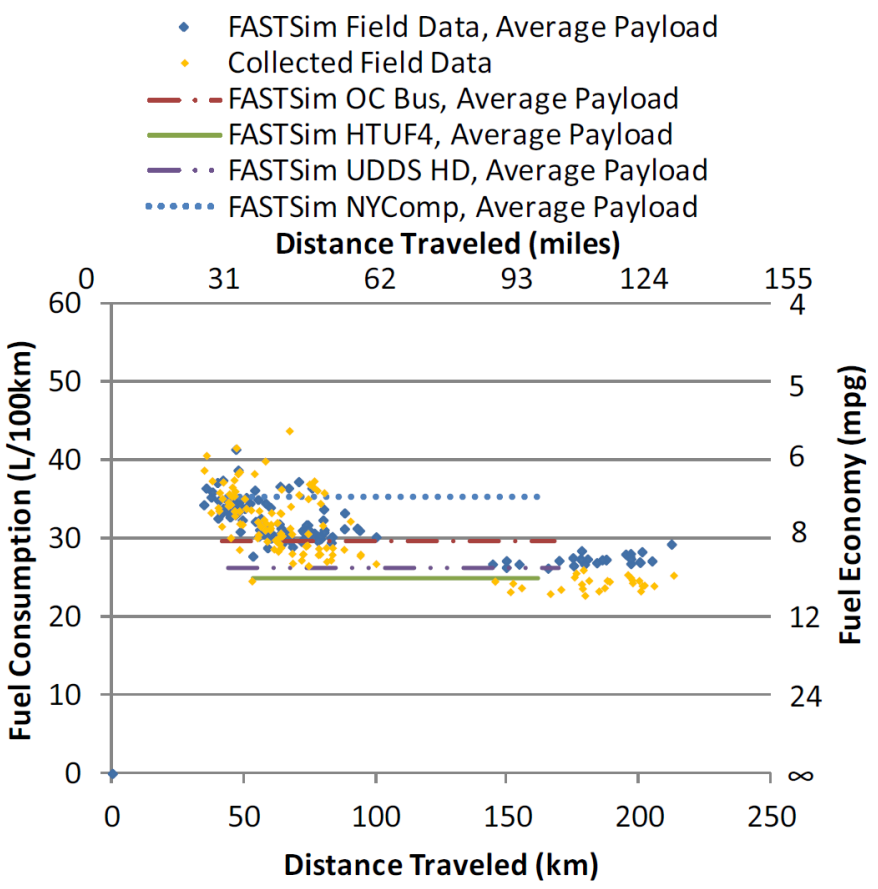

Figure 6. Comparison of stock-cycle to field-cycle fuel consumption: addition of the NYComp cycle to the other stock cycles better captures the full range of field-cycle fuel consumption

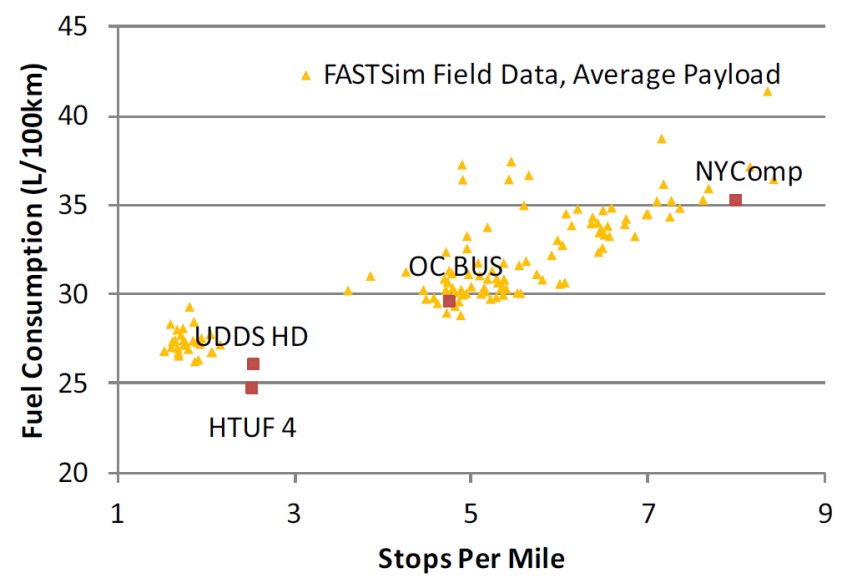

Figure 7. Comparison of stock-cycle to field-cycle stops per mile: addition of the NYComp cycle to the other stock cycles better captures the full range of field-cycle stops per mile

\section{Development of the Design and Cost Matrix}

The above analysis led to selection of the four stock cycles used for the design matrix summarized in Table 3 . Figure 8 and Figure 9 show the two design matrix stock cycles that were not pictured earlier. It should be noted that the additional battery energy array is of varied step size. There is a finer resolution at lower battery capacities (e.g., $12.5 \mathrm{kWh}, 22.5 \mathrm{kWh}, 42.5 \mathrm{kWh}$, and $62.5 \mathrm{kWh}$ ), because it is expected that the battery energy is a key cost driver in the total cost of ownership. To be consistent with commercially available battery offerings, the power-toenergy ratio is set at a floor of 1.125 . The battery power was held constant at $30 \mathrm{~kW}$, unless the power-to-energy ratio fell below the 1.125 limit. If the ratio fell below this limit, the battery power was increased to compensate. Based on the previous results showing little impact from variable motor size, the motor power was held constant in this analysis at a level matched to the baseline $30-\mathrm{kW}$ battery power [ㅁ].

Two cost scenarios were developed to represent a fair range of costs (Table 4). Baseline and future fuel/electricity costs are yearly highs for 2011 and 2030, respectively [ㅇ]. The baseline battery cost-per-kWh value is taken from a 2011 DOE Annual Merit Review Plenary Presentation, and the future battery cost assumption is cited from the United States Advanced Battery Consortium (USABC) Goals for Advanced Batteries for EVs [ㅁ-10].

Table 5 lists additional assumptions used in the analysis. Note that for the battery, FASTSim assumes a base packaging cost plus a cost-per-kWh and cost-per-kW, so the simplified battery cost assumptions from Table 4 were manipulated into this form for the analysis.

Table 3. Design Matrix for PHEVs

\begin{tabular}{|l|l|}
\hline Drive cycles & $\begin{array}{l}\text { UDDS HD, HTUF 4, OC } \\
\text { Bus, NYComp }\end{array}$ \\
\hline Daily distance traveled & $40,80,120,160 \mathrm{~km}$ \\
\hline Additional battery energy & $10,20,40,60 \mathrm{kWh}$ \\
\hline Battery power & $\mathrm{MAX}(30 \mathrm{~kW}$, Energy $\times \mathrm{P} / \mathrm{E})$ \\
\hline $\begin{array}{l}\text { Battery power-to-energy } \\
\text { ratio }\end{array}$ & $1.125^{1}$ \\
\hline
\end{tabular}

${ }^{1}$ Smith Newton battery 


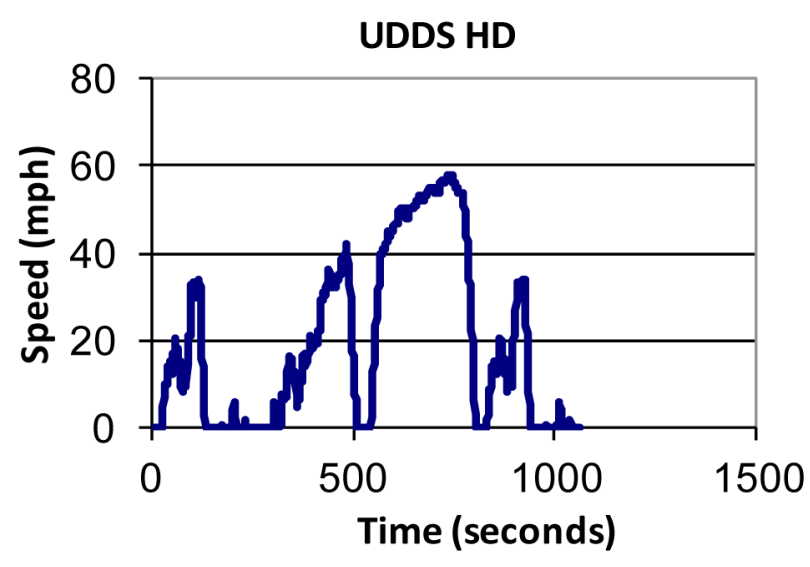

Figure 8.UDDS HD profile

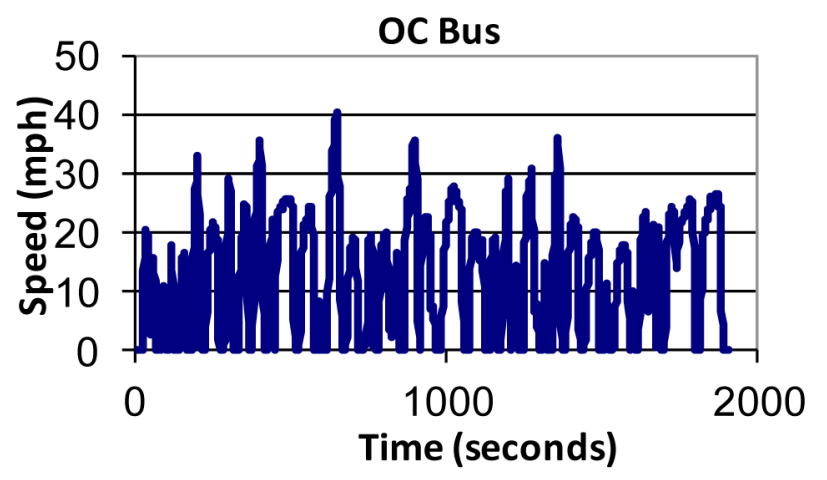

Figure 9. OC Bus profile

Table 4. Cost Matrix

\begin{tabular}{|l|c|c|c|}
\hline Scenario & $\begin{array}{c}\text { Battery } \\
\text { Cost }\end{array}$ & $\begin{array}{c}\text { Diesel Fuel } \\
\text { Cost }\end{array}$ & $\begin{array}{c}\text { Electricity } \\
\text { Cost }\end{array}$ \\
\hline Baseline & $\$ 700 / \mathrm{kWh}$ & $\begin{array}{c}\$ 0.85 / \mathrm{L} \\
(\$ 3.23 / \mathrm{gal})\end{array}$ & $\$ 0.11 / \mathrm{kWh}$ \\
\hline Future & $\$ 100 / \mathrm{kWh}$ & $\begin{array}{c}\$ 1.37 / \mathrm{L} \\
(\$ 5.19 / \mathrm{gal})\end{array}$ & $\$ 0.11 / \mathrm{kWh}$ \\
\hline
\end{tabular}

Table 5. Additional Assumptions

\begin{tabular}{|l|c|}
\hline Vehicle life (years) & 15 \\
\hline Battery cost & $\begin{array}{c}\$ 22 / \mathrm{kW} \times(\mathrm{kW})+\text { scenario } \$ / \mathrm{kWh} \\
*(\mathrm{kWh})+\$ 680\end{array}$ \\
\hline Battery mass & $75 \mathrm{~kg}+8 \mathrm{~kg} / \mathrm{kWh}$ \\
\hline $\begin{array}{l}\text { Motor and controller } \\
\text { cost }\end{array}$ & $\$ 21.7 / \mathrm{kW}+\$ 425$ \\
\hline Markup factor & 1.5 \\
\hline Discount rate & $8 \%$ \\
\hline Charger efficiency & 0.9 \\
\hline
\end{tabular}

\section{Battery-Life Model and Replacements}

Battery life and replacements were estimated using cycle-wear data from Johnson Controls, as shown in Figure 10. The curve labeled "Original" represents data published by Johnson Controls. These data were obtained at the cell level and do not capture variations in calendar-life, temperature, or power-level on life. To help account for those impacts, the "Today's Adjusted" curve was created by adjusting the "Original" case to match published data for the Nissan LEAF and the Chevy Volt battery life expectations [11].

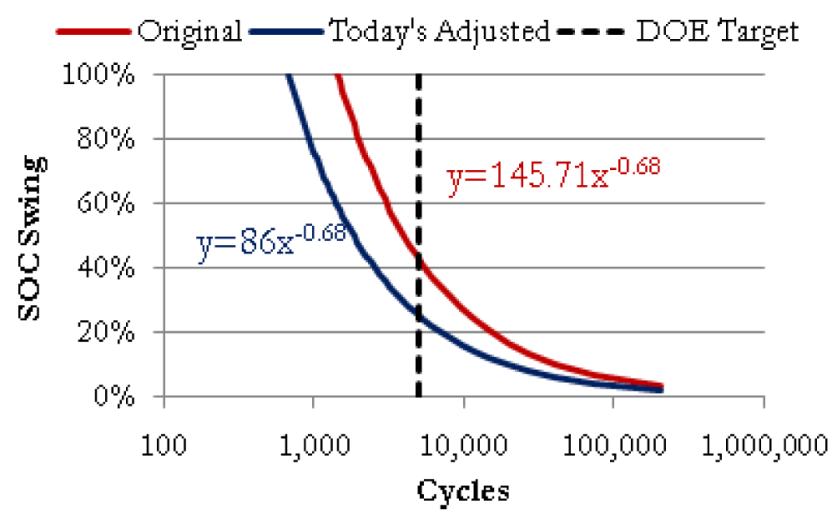

Figure 10. Battery cycle life curves

By solving for the number of cycles $(x)$ and plugging in the state-of-charge (SOC) swing (y), the model can calculate the percent wear for every charge fluctuation. The publication on the previous investigation describes the iterative procedure for using this wear prediction to determine the permissible SOC swing for a given battery size and use profile, or whether a battery replacement would be necessary in order to satisfy the vehicle life requirement []].

$$
x=\left(\frac{86}{y}\right)^{\frac{1}{0.68}}
$$

\section{RESULTS}

This section presents analytical results for the specified range of vehicle configuration, usage, and economic scenarios.

\section{Lifetime Cost Analysis}

Two different methods compare costs: a fuel savings comparison, and a relative comparison with the baseline diesel conventional. The relative comparison subtracts the discounted lifetime fuel costs for the baseline conventional diesel from the comparable lifetime energy and incremental capital costs of the $\mathrm{P} / \mathrm{HEV}$ version (including battery and motor, fuel, and 
electricity). Lastly, the fuel savings comparison allows us to determine how many liters of diesel fuel were saved by the P/ $\mathrm{HEV}$ when compared to the conventional diesel.

\section{Vehicle Nomenclature}

The presented column charts have several dimensions. Along the $x$ axis, the results fall into four groups of increasing distance driven. For each distance driven, there are five levels of battery energy. For each battery energy level, there are four cycles that increase in kinetic intensity. It should be noted that the +40 and $+60-\mathrm{kWh}$ scenarios resulted in a battery power-to-energy ratio of less than 1.125 . For these cases, the battery power was increased as described previously under the sub-section titled "Development of the Design and Cost Matrix."

\section{Fuel Use Savings from Drivetrain Electrification}

Adding an electric drivetrain saves fuel. Figure 11 plots lifetime fuel savings in liters. As expected, the longer the distance traveled, the greater the fuel savings. (Note that even after a PHEV depletes its battery, further driving continues to accumulate fuel savings relative to the baseline conventional vehicle thanks to hybridization fuel saving techniques such as regenerative braking). Lifetime fuel savings also tend to increase with larger battery size and with higher cycle kinetic intensity (which, again, increases the hybridization fuel savings potential).

\section{When are $\mathrm{P} / \mathrm{HEVs}$ Cost-Effective?}

Figure 12 and Figure 14 show the difference between the P/ HEV lifetime cost and the conventional diesel lifetime cost. The $\mathrm{P} / \mathrm{HEV}$ lifetime cost is composed of upfront battery and motor costs, liquid fuel cost, electricity cost, and a battery replacement cost, as applicable; the conventional diesel lifetime cost is comprised of the cost of liquid fuel. A positive value indicates that the $\mathrm{P} / \mathrm{HEV}$ is more expensive.

Assuming $\$ 700 / \mathrm{kWh}$ battery costs and $\$ 3.23 /$ gal fuel costs, Figure 12 shows that all HEV scenarios pay back, and that the 12.5-kWh battery PHEV configuration recoups the additional battery and motor cost when it can accumulate fuel savings over 50 miles ( 80 kilometers) daily. The $22.5-\mathrm{kWh}$ battery PHEV configuration recoups the additional cost when it can accumulate fuel savings over 50 miles daily, but only on the most kinetically intense cycle considered-the NYComp cycle. When the vehicles travel longer distances per day, more PHEV configurations pay off. As indicated by the density plot in Figure 13, some real-world drive cycles coincide with the conditions that result in payback for the $12.5-\mathrm{kWh}$ battery PHEV under these baseline cost assumptions. Red tiles indicate a larger density of field data points coinciding with the indicated combination of drive profile kinetic intensity and daily distance. Note that the longer daily distance routes seen in the field tend to be characterized by lower kinetic intensities (the higher density red areas fall lower on the y-axis as the daily distance traveled increases).

With the aggressive future cost assumptions of $\$ 100 / \mathrm{kWh}$ for batteries and $\$ 5.19 / \mathrm{gal}$ for diesel fuel, Figure 14 shows that all of the simulated usage patterns pay off the incremental cost of the $\mathrm{P} / \mathrm{HEV}$ from accumulated lifetime fuel savings.

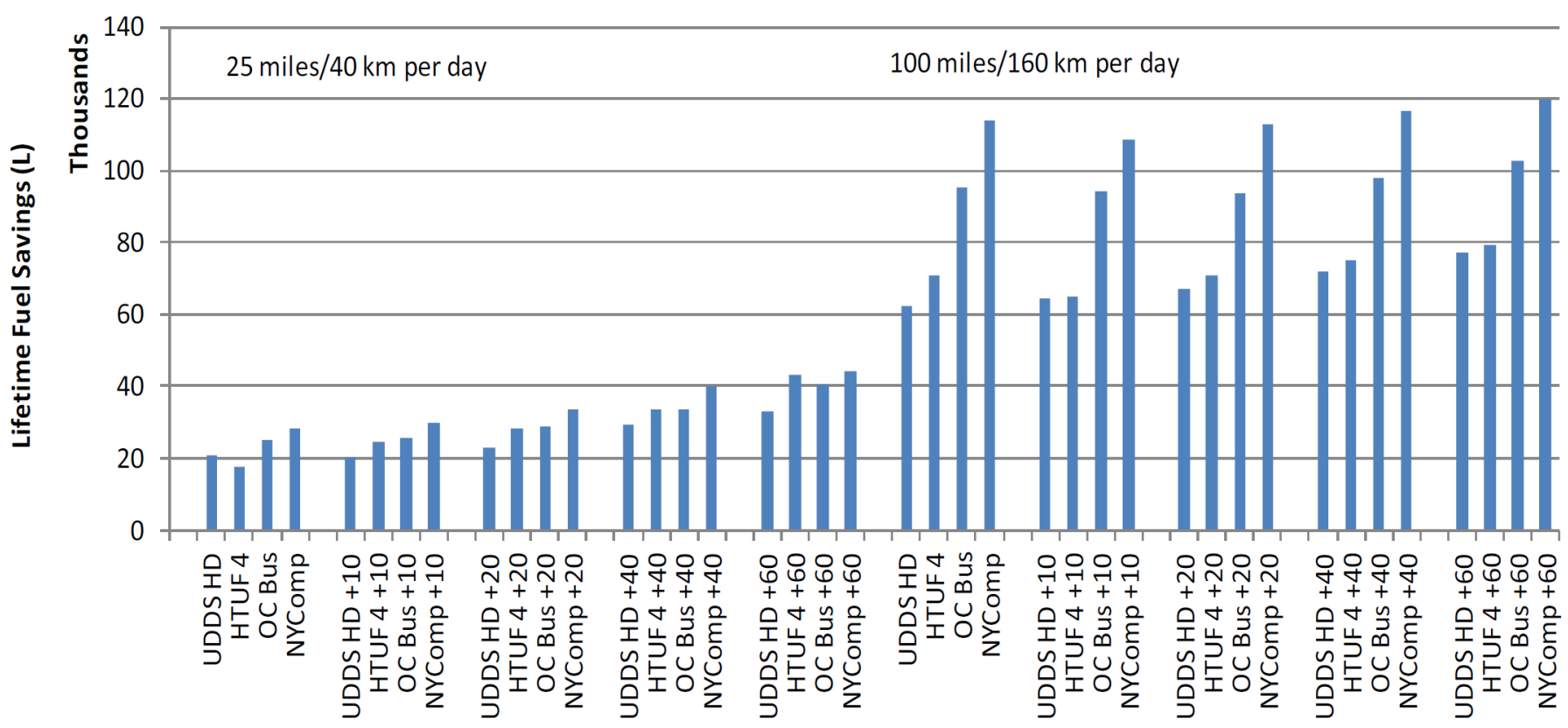

Figure 11. Lifetime fuel savings: Diesel PHEV 


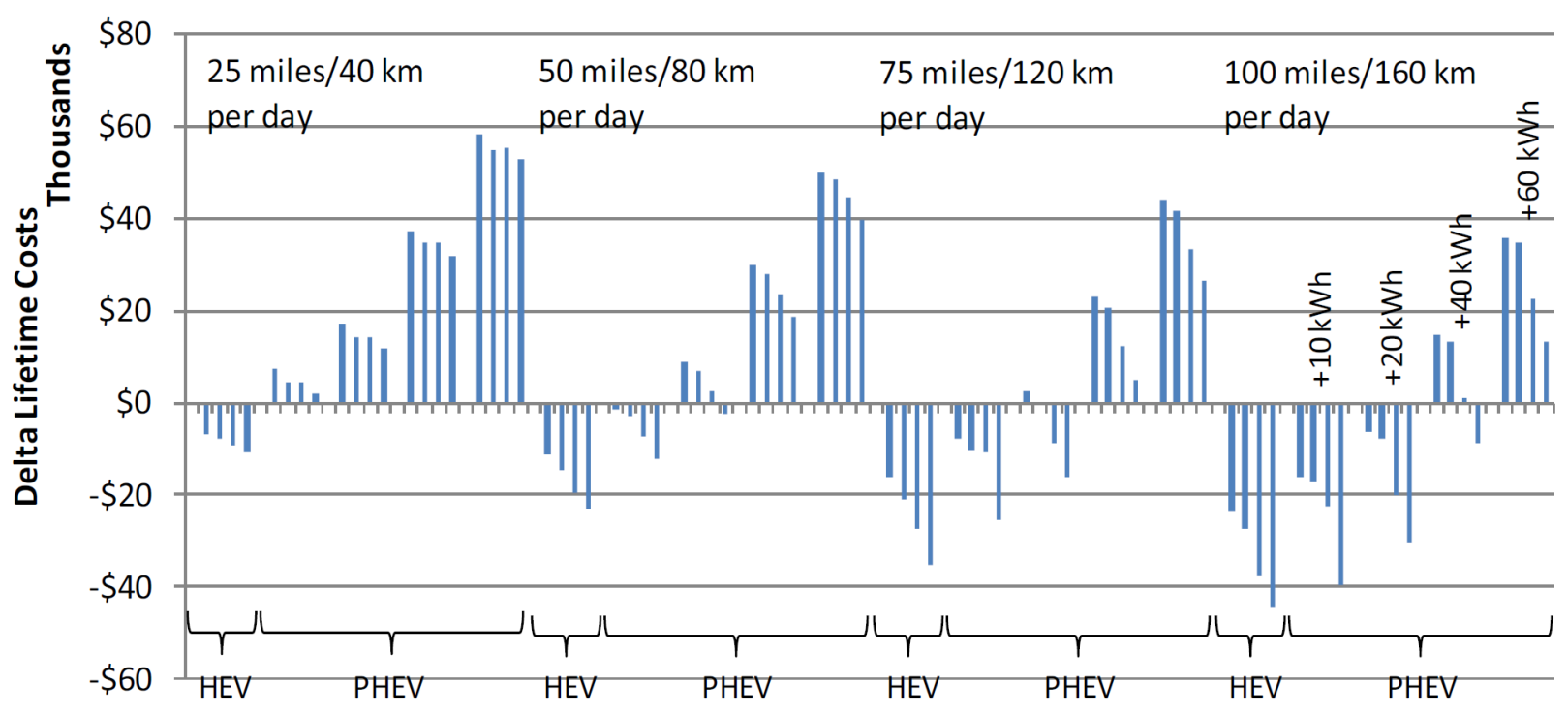

\section{Cycle Order}

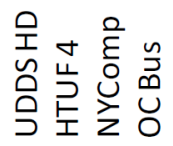

Figure 12. Incremental lifetime cost: Diesel PHEV, baseline cost scenario

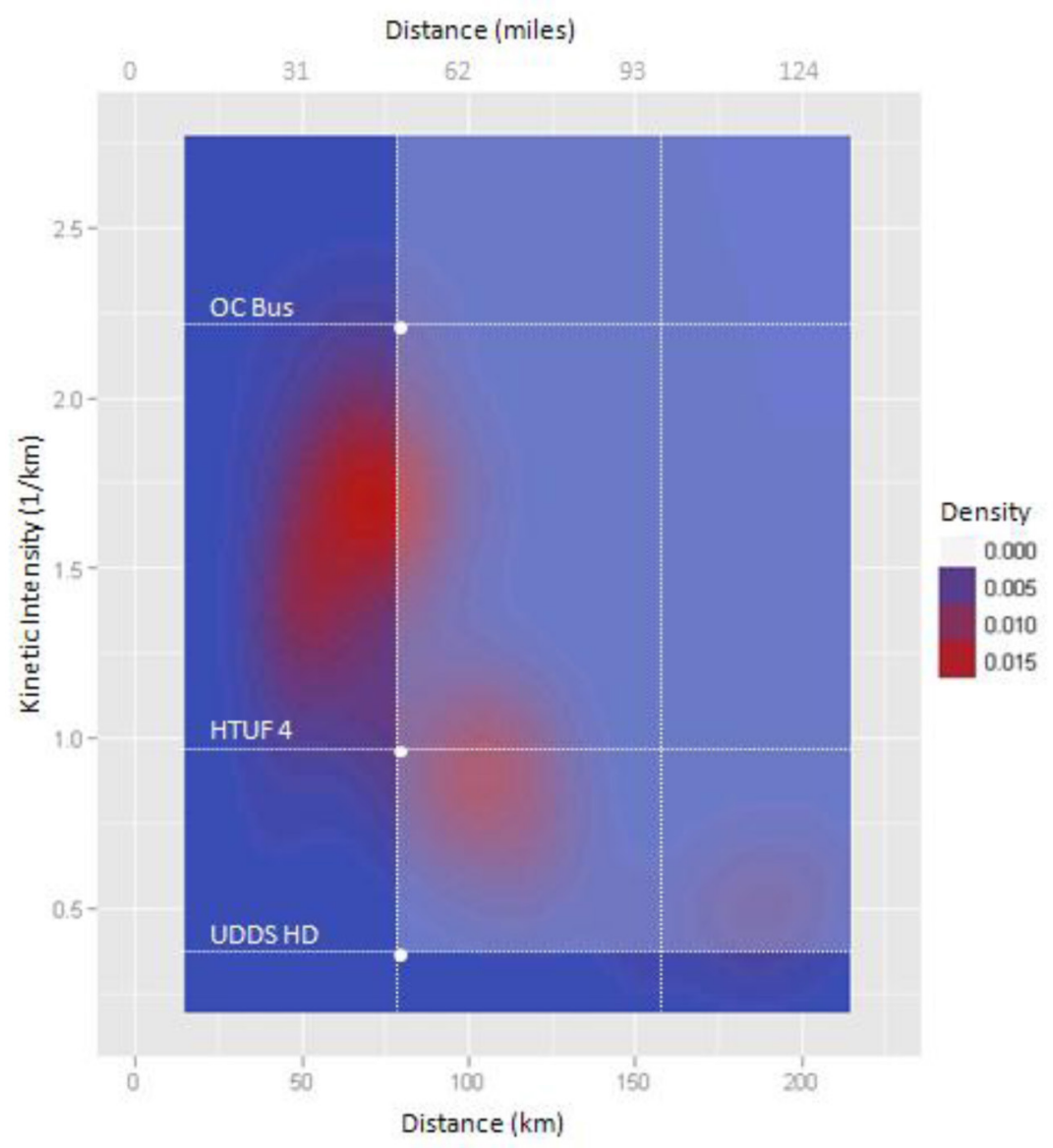

Figure 13. Density plot of real-world drive cycles relative to their travel distance and kinetic intensity (Note that some cycles fall into the shaded area, which corresponds with cost-effective usage scenarios for a 12.5-kWh diesel PHEV with no battery replacement under the baseline cost assumptions.) 


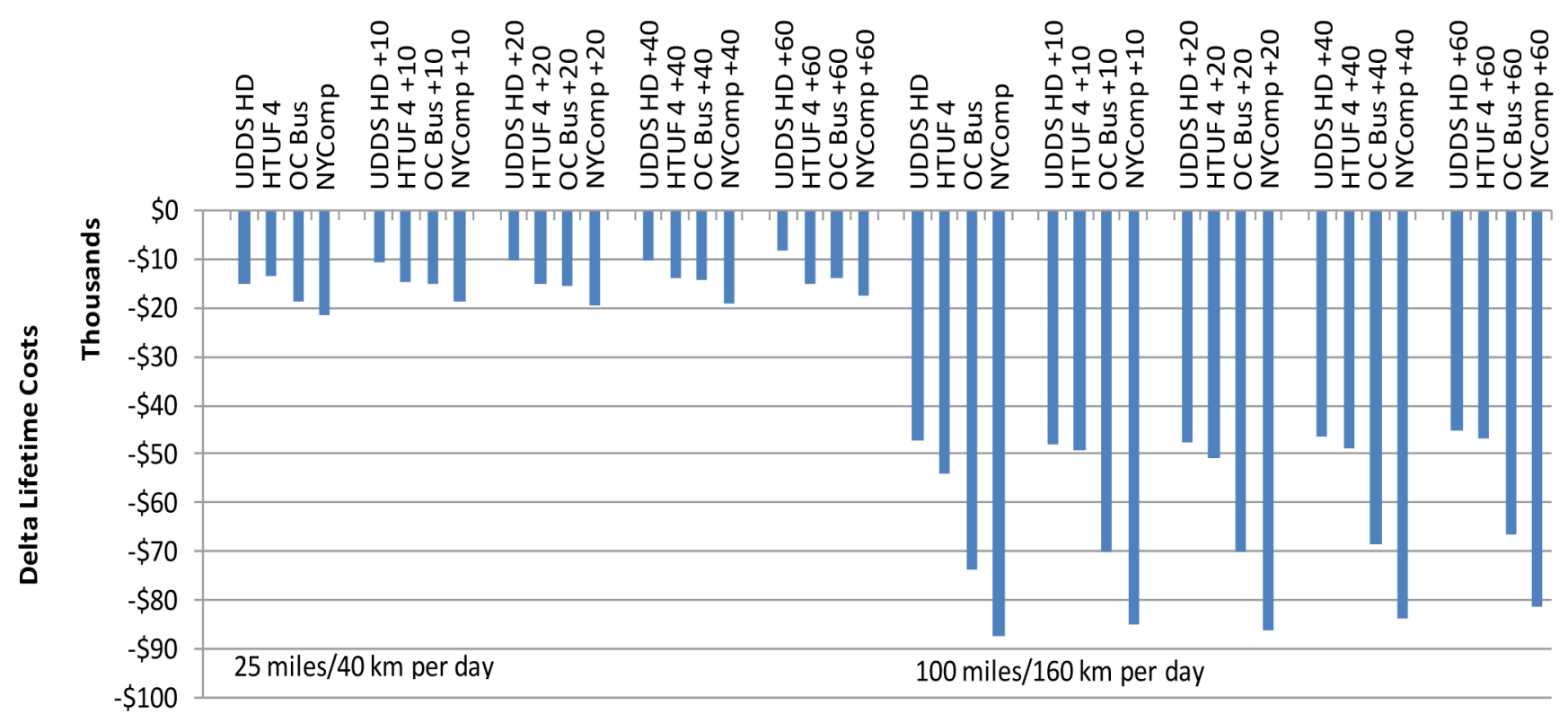

Figure 14. Incremental cost: Diesel PHEV, future scenario

\section{Break-Even Point Analysis}

To evaluate the break-even point, we assume the baseline diesel fuel cost (\$3.23/gal) and solve for the battery cost per $\mathrm{kWh}$ that would make PHEVs economical under the given usage pattern. Figure 15 and Figure 16 plot the break-even cost per $\mathrm{kWh}$ results against daily distance traveled.

In Figure 15, the lower the battery energy, the higher the cost per kWh that can be tolerated to break even. In other words, a smaller battery allows for more money to be spent per kWh on the battery cost for any given usage pattern.

The bold dashed line at $\$ 700 / \mathrm{kWh}$ highlights the baseline battery cost per $\mathrm{kWh}$ assumption. At this cost, the $12.5-\mathrm{kWh}$ battery, $149-\mathrm{kW}$ engine configuration pays back at a daily travel distance of just under 50 miles on the HTUF 4 cycle, and the $22.5-\mathrm{kWh}$ configuration pays back at just less than 80 miles.

The dashed lines in Figure 15 represent break-even cost curves for the downsized engine scenario. In general, downsizing results in a higher tolerated cost per $\mathrm{kWh}$ break-even point due to the higher fuel savings. Downsizing the engine on the 12.5kWh configuration, HTUF 4 usage scenario increased battery use (and wear), resulting in a mandatory battery replacement for daily travel distances greater than 80 miles in order to meet the 15 -year life requirement. The battery replacement required for this scenario results in a lower cost per $\mathrm{kWh}$ break-even point at 100 miles traveled (assuming the same cost per $\mathrm{kWh}$ for both the original and the replacement battery).

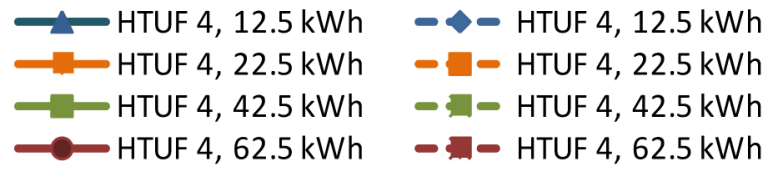

Daily Distance Traveled (km)

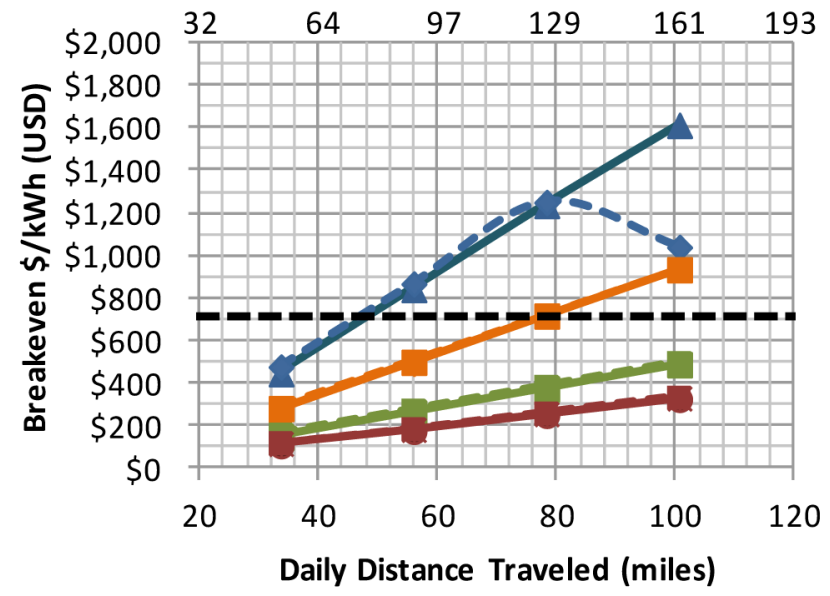

Figure 15. Impact of PHEV battery size, daily travel distance and engine downsizing on the $\$ / k W h$ break-even point

In Figure 16, the drive cycles listed in the legend are in order of increasing kinetic intensity. The higher the cycle's kinetic intensity, the higher the battery cost per kWh that is tolerated. 


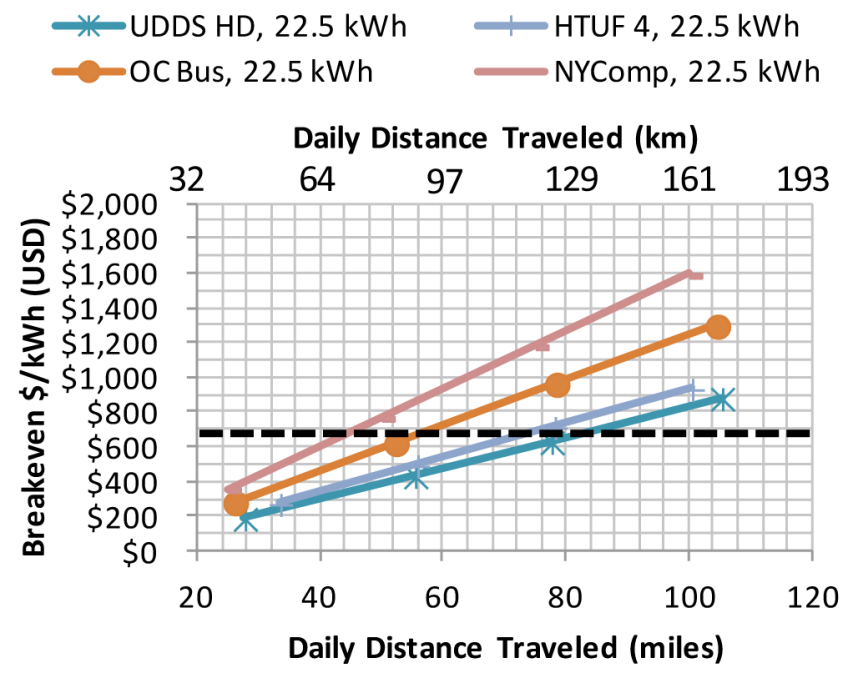

Figure 16. Impact of drive-cycle kinetic intensity on the break-even point: 149-kW engine, baseline scenario

\section{CONCLUSIONS}

This research effort leveraged expertise from multiple NREL teams related to modeling, laboratory testing, field evaluation and economic analysis of medium-duty commercial vehicles. The research showed that electrification of a conventional diesel parcel delivery truck powertrain could result in lifetime fuel savings as high as 20,000 gallons (75,000 liters) for a single vehicle, but may not be economical, depending on battery costs, the daily distance traveled, and the drive-cycle kinetic intensity. The research team identified the battery cost per $\mathrm{kWh}$ required to achieve cost-effectiveness under multiple scenarios. The team also highlighted that long daily travel distances and high cycle kinetic intensity each improve the payback picture, but few of the real-world use profiles simultaneously possess both of these characteristics. Factors such as higher reference fuel cost will also tend to increase the battery cost per $\mathrm{kWh}$ that can be tolerated. Vehicle designs showing promising payback potential (relative to the baseline conventional configuration over a 15-year vehicle life) included the HEV across all of the scenarios considered, and the $12.5-\mathrm{kWh}$ PHEV configuration when driven at least 50 miles per day (assuming battery cost $\leq \$ 700 / \mathrm{kWh}$, diesel fuel cost $\geq \$ 3.23 /$ gal and drive profile kinetic intensity equal or greater than that of the UDDS HD cycle).

\section{REFERENCES}

1. "Vehicle Systems Analysis." National Renewable Energy Laboratory. Accessed December 2012: http://www.nrel. gov/vehiclesandfuels/vsa/
2. "Fleet Test and Evaluation." National Renewable Energy Laboratory. Accessed December 2012: http://www.nrel. gov/vehiclesandfuels/fleettest/

3. "ReFUEL Laboratory." National Renewable Energy Laboratory. Accessed December 2012: http://www.nrel. gov/vehiclesandfuels/refuellab/

4. "Future Automotive Systems Technology Simulator (FASTSim)." National Renewable Energy Laboratory. Accessed December 2012: http://www.nrel.gov/ vehiclesandfuels/vsa/fastsim.html (website with model description and open-source download file)

5. Lammert, M. and Walkowicz, K. Eighteen-Month Final Evaluation of UPS Second Generation Diesel Hybrid Electric Delivery Vans. NREL/TP-5400-55658. Golden, CO: National Renewable Energy Laboratory, 2012. Accessed December 2012: http://www.nrel.gov/docs/ fy12osti/55658.pdf.

6. Ramroth, L.A.; Gonder, J.; and Brooker, A. "Integrated Testing Simulation and Analysis of Electric Drive Options for Medium-Duty Parcel Delivery Vehicles." Preprint. Prepared for the Proceedings of the International Battery, Hybrid and Fuel Cell Electric Vehicle Symposium 26 (EVS-26), May 2012 Golden, CO: National Renewable Energy Laboratory http://www.nrel. gov/docs/fy12osti/53983.pdf.

7. O'Keefe, M., Simpson, A., Kelly, K., and Pedersen, D., "Duty Cycle Characterization and Evaluation Towards Heavy Hybrid Vehicle Applications," SAE Technical Paper 2007-01-0302, 2007, doi:10.4271/2007-01-0302.

8. “Annual Energy Outlook 2011.” U.S. Energy Information Administration. Table 20, Energy Prices by Sector and Source, United States, Reference Case. Current 2011, Future 2030. www.eia.gov/forecasts/ aeo/topic_prices.cfm. (Direct Link www.eia.gov/oiaf/ aeo/tablebrowser/aeo query server/?event=ehExcel. getFile\&study $=$ AEO2011\&region $=1-0 \&$ cases $=$ ref2011d020911a\&table $=3-$ AEO2011\&yearFilter $=0$ )

9. Howell, D. "Hybrid Electric Systems." Presented at the 2011 DOE Annual Merit Review Plenary Presentation. May 2011. Accessed December 2012: http://www1.eere. energy.gov/vehiclesandfuels/pdfs/merit_review_2011/ plenary/vtpn07_howell_ft_2011_o.pdf.

10. "Electrochemical Energy Storage Tech Team." United States Council for Automotive Research LLC. Accessed December 2012: www.uscar.org/guest/view_team. php?teams_id=11 (See Energy Storage System Goals and USABC Goals for Advanced Batteries for EVs.) 
11. O'Keefe, M.; Brooker, A.; Johnson, C.; Mendelsohn, M.; Neubauer, J.; and Pesaran, A. "Battery Ownership Model: A Tool for Evaluating the Economics of Electrified Vehicles and Related Infrastructure." Presented at the 25th International Battery, Hybrid and Fuel Cell Electric Vehicle Symposium \& Exposition, Shenzhen, China, November 5-9, 2010. NREL/CP-5400-49127. Golden, CO: National Renewable Energy Laboratory, January, 2011. Accessed December 2012: http://www.nrel.gov/ docs/fy11osti/49127.pdf.

\section{CONTACT INFORMATION}

Laurie Ramroth worked as a research engineer for the Center for Transportation Technologies and Systems (CTTS) at the National Renewable Energy Laboratory (NREL) through November 2012. Laurie currently works for Ford Motor Company as a fuel economy attribute engineer. Jeffrey Gonder leads the Vehicle Systems Analysis team within CTTS at NREL and may be contacted with any questions pertaining to this research at jeff.gonder@,nrel.gov.

\section{ACKNOWLEDGMENTS}

The authors respectfully acknowledge the contributions of NREL's ReFUEL Laboratory and Fleet Test and Evaluation teams. Their work was essential to this analysis. The authors also gratefully acknowledge the programmatic support of the U.S. Department of Energy, Office of Energy Efficiency and Renewable Energy, Vehicle Technologies Program. Particular thanks go to Vehicle Systems activity managers David Anderson and Lee Slezak for their guidance and support.

\section{DEFINITIONS/ABBREVIATIONS}

DOE - Department of Energy

FASTSim - Future Automotive Systems Technology Simulator

GPS - Global-Positioning System

HEV - Hybrid electric vehicle

NREL - National Renewable Energy Laboratory

PHEV - Plug-in hybrid electric vehicle
P/HEV - Collective abbreviation for hybrid and plug-in hybrid electric vehicle scenarios

ReFUEL - Renewable Fuels and Lubricants Laboratory UPS - United Parcel Service

USABC - United States Advanced Battery Consortium VSST - Vehicle Systems Simulation and Testing
The Engineering Meetings Board has approved this paper for publication. It has successfully completed SAE's peer review process under the supervision of the session organizer. This process requires a minimum of three (3) reviews by industry experts.

All rights reserved. No part of this publication may be reproduced, stored in a retrieval system, or transmitted, in any form or by any means, electronic, mechanical, photocopying, recording, or otherwise, without the prior written permission of SAE.

ISSN 0148-7191
Positions and opinions advanced in this paper are those of the author(s) and not necessarily those of SAE. The author is solely responsible for the content of the paper SAE Customer Service:

Tel: 877-606-7323 (inside USA and Canada)

Tel: 724-776-4970 (outside USA)

Fax: 724-776-0790

Email: CustomerService@sae.org

SAE Web Address: http://www.sae.org

Printed in USA 